\title{
РАДИАЦИОННО-ИНДУЦИРОВАННОЕ ДВИЖЕНИЕ ЖИДКИХ ВКЛЮЧЕНИЙ В ЩЕЛОЧНО-ГАЛОИДНЫХ КРИСТАЛЛАХ
}

\author{
А.П. Кулик ${ }^{1 *}$, О.В. Подшивалова ${ }^{2}$ И.Г. Марченко ${ }^{1,3 *}$ \\ ${ }^{1}$ Харьковский национальный университет им. В.Н. Каразина, Харьков, Украина; \\ ${ }^{2}$ Национальный аэрокосмический университет им. Н.Е. Жуковского \\ "Харьковский авиационный институт», Харьков, Украина; \\ ${ }^{3}$ Национальный научный центр «Харьковский физико-технический институт», \\ Харьков, Украина \\ E-mail: *kulykop@gmail.com; *march@kipt.kharkov.ua
}

Изучено радиационно-стимулированное поведение жидких включений в монокристаллах $\mathrm{KCl}$. Показано, что под действием облучения включения становятся подвижными. Это может приводить к миграции таких объектов на границу материала и выходу радиоактивных элементов из захоронения. Исследованы траектории самопроизвольной миграции включений различных размеров в кристаллах, облученных электронами и $\gamma$-квантами.

\section{ВВЕДЕНИЕ}

Облучение существенно влияет на изменение свойств исходного материала [1]. Многие процессы ускоряются под воздействием нейтронного, электронного или гамма-излучения. Хорошо известны явления радиационно-ускоренной диффузии, ползучести, охрупчивания и др. [2-5].

Вместе с тем облучение может оказывать влияние не только на диффузионную подвижность отдельных атомов или кластеров, но и на поведение макровключений. Такие включения присутствуют во многих природных минералах, в частности, в отложениях геологического происхождения. Последние могут использоваться для захоронения радиоактивных отходов [6]. С течением времени в хранилищах продолжаются ядерные реакции. Это может приводить к активизации процессов взаимодействия вещества матрицы с продуктами захоронения, в частности, к движению включений, выходу их на свободные поверхности и выбросу радиоактивных веществ в атмосферу. В этой связи представляет интерес исследование влияния радиационных дефектов на процессы движения жидких включений.

Целью работы являлось исследование радиационно-индуцированного движения жидких включений в монокристаллах $\mathrm{KCl}$ под воздействием облучения $\gamma$-квантами и электронами.

\section{ПОДГОТОВКА ОБРАЗЦОВ}

Жидкие включения в монокристаллах $\mathrm{KCl}$ создавали методом залечивания трещины [7]. Для этого в образце формировали незавершенную трещину, которая под действием капиллярных сил заполнялась дистиллированной водой. В процессе выдержки образца при комнатной температуре (около десяти суток) происходило залечивание трещины, сопровождавшееся образованием в ее устье включений насыщенного раствора $\mathrm{KCl}$ в воде. Образовавшиеся включения имели размеры от 3 до 100 мкм.

Движение жидких включений исследовали в поле температурного градиента, величина которого варьировалась от $2 \cdot 10^{2}$ до $2 \cdot 10^{4} \mathrm{~K} /$ м. Температурный градиент в образце создавался приведением его противоположных граней в контакт с нагревателем и холодильником, который охлаждался проточной водой. Для определения величины температурного градиента $(\nabla T)$ выкаливали контрольные кристаллы таких же размеров, как и образцы с включениями. В контрольные образцы впаивали две термопары. Снимая показания с термопар при известном расстоянии между ними, вычисляли величину температурного градиента в образцах.

Наблюдение за движением включений осуществляли с помощью оптического микроскопа на просвет. Для этого нагреватель, образец и холодильник закрепляли на предметном столике микроскопа. Образцы фиксировали таким образом, чтобы градиент температуры был ориентирован в плоскости $\{100\}$ параллельно направлению $\langle 100\rangle$.

Дислокационную структуру исследуемых кристаллов контролировали химическим травлением. В качестве травителя использовали насыщенный раствор $\mathrm{PlCl}_{2}$ в метиловом спирте. После травления образец промывали в смеси этилового и амилового спиртов.

\section{ИСТОЧНИКИ СЛОЕВ РАСТВОРЕНИЯ}

Известно, что послойный рост кристаллов осуществляется либо механизмом двумерного зародышеобразования, либо на дислокациях, имеющих винтовую компоненту вектора Бюргерса [8]. Считая включение «отрицательным кристаллом», процесс его движения можно рассматривать как одновременный рост лобовой поверхности и растворение тыльной. В связи с этим растворение матрицы на лобовой поверхности включения моделирует процесс дислокационного роста, поскольку при движущих силах, реализуемых в данных опытах, другие источники растворения кроме винтовых дислокаций не могут проявить себя $[2,9]$. Рост кристалла на тыльной поверхности включения происходит в результате движения ступеней, формирующихся в углах между тыльной и боковыми поверхностями. Этот процесс моделирует 
растворение микрокристалла, когда источником ступеней являются его ребра.

Дислокационный механизм растворения лобовых поверхностей движущихся включений непосредственно подтверждают следующие опыты. Были проведены исследования дислокационной структуры большого количества монокристаллов $\mathrm{KCl} \mathrm{c} \mathrm{тем,} \mathrm{чтобы} \mathrm{выбрать} \mathrm{кристалл} \mathrm{с}$ неравномерным распределением дислокаций. Из такого кристалла выкалывали образец и создавали в нем включения. После скалывания поверхность типа (100), вблизи которой находился ансамбль включений, выбранный для наблюдения, протравливали на дислокации (рис. 1, а). Затем образец помещали в поле температурного градиента, направленного таким образом, чтобы включения при движении могли пересекать как сильнодислоцированную область образца, так и слабодислоцированную. Наблюдения показали, что движущиеся включения, подойдя к практически бездислокационной области кристалла, останавливаются (см. рис. 1). Очевидно, что включения, изначально не пересекаемые дислокациями, вообще не должны приходить в движение. Включения также должны оставаться неподвижными, если расстояние от точки выхода винтовой дислокации до края грани или до точки выхода дислокации противоположного знака меньше порогового при заданных движущих силах [9].

\section{МЕТОДИКА ЭКСПЕРИМЕНТА}

Одним из типов дефектов, образующихся при воздействии на щелочно-галоидные кристаллы ионизирующего излучения, являются электронные и дырочные центры окраски. Будучи точечными дефектами, центры окраски не создают на поверхности кристалла дополнительных источников ступеней. Однако наличие их в кристалле может изменить величины кинетических характеристик процессов растворения, в частности, кинетического коэффициента ступени, что приведет к изменению скорости растворения кристалла. Кроме того, запасенная в кристалле при облучении энергия должна изменять условия термодинамического равновесия кристалла с раствором, т. е. растворимость облученного кристалла должна быть выше, чем необлученного.

Опыты проводили с жидкими включениями в монокристаллах $\mathrm{KCl}$, подвергавшихся облучению $\gamma$-квантами от источника ${ }^{60} \mathrm{Co}$ и ускоренными электронами энергией 10 МэВ при интегральной плотности тока $5 \cdot 10^{-2} \mathrm{~A} / \mathrm{M}^{2}$ (суммарная доза достигала величины $10^{21} \mathrm{M}^{-2}$ ). В результате облучения образцы окрашивались. Тип и концентрацию центров окраски определяли по спектрам оптического поглощения облученных кристаллов, используя известную методику [10]. Во всех опытах основными центрами окраски являлись электронные F-центры и дырочные $\mathrm{V}_{3}$-центры. Концентрации идентифицируемых $\mathrm{R}_{1^{-}}, \mathrm{R}_{2^{-}}$и $\mathrm{M}$ центров оказывались существенно меньшими. В зависимости от дозы и вида облучения концентрации F- и $\mathrm{V}_{3}$-центров были примерно

одинаковыми и варьировались в пределах $10^{21} \ldots 10^{23} \mathrm{M}^{-3}$.

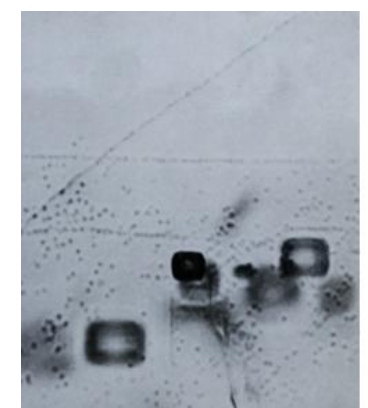

$a$
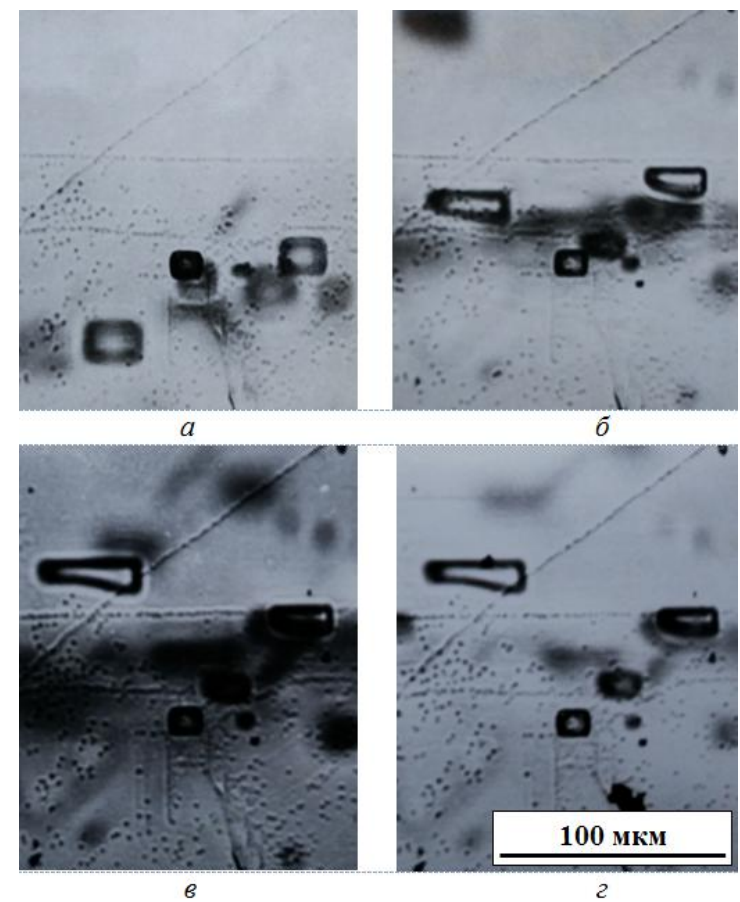

$\sigma$

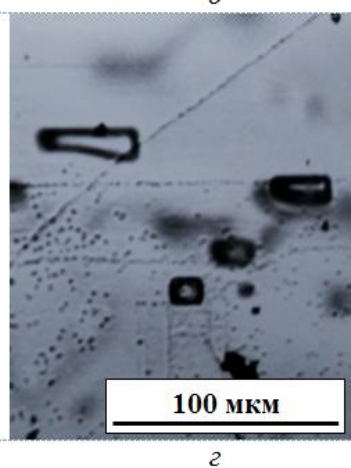

Рис. 1. Движение включений в поле температурного градиента в монокристалле $\mathrm{KCl}$ с неравномерным распределением дислокаџий:

$a$-исходное состояние; б-через 11; в-16; г-25 ч

Контрольную серию опытов проводили с жидкими включениями в монокристаллах $\mathrm{KCl}$, в которых создавали только электронные центры окраски в результате аддитивного окрашивания в парах щелочного металла [11]. Для этого из кристалла $\mathrm{KCl}$ выкалывали пластинку и помещали ее в контейнер из нержавеющей стали, на дне которого находился металлический калий. Контейнер плотно закрывался завинчивающейся крышкой. Контроль температуры осуществляли при помощи встроенной термопары. Контейнер отжигали в атмосфере аргона при $T=600^{\circ} \mathrm{C}$ в течение одного часа. Охлаждение образца до комнатной температуры происходило вместе с печью.

Наблюдение за включениями в окрашенных образцах осуществляли как в поле градиента температуры, так и в изотермических условиях. В аддитивно окрашенных кристаллах направление температурного градиента задавали перпендикулярно плоскости трещины. Это обусловлено тем, что в отличие от облученных кристаллов (облучались образцы с уже созданными включениями) в аддитивно окрашенных кристаллах при залечивании трещины включения оказываются в перекристаллизованной области, не содержащей центры окраски.

\section{ДВИЖЕНИЕ И ФОРМОИЗМЕНЕНИЕ ВКЛЮЧЕНИЙ В КРИСТАЛЛАХ С ЦЕНТРАМИ ОКРАСКИ}

При движении включения в окрашенном кристалле на его лобовой поверхности растворяется кристалл с центрами окраски, а на тыльной 
поверхности естественно растет кристалл без них. Вследствие этого за движущимся включением образуются просветленные следы (рис. 2). При этом наблюдается еще одна особенность процесса: в объеме жидкого включения образуется пузырек газа. При движении такого включения может происходить его распад на жидкое и газожидкое включения с большим содержанием газа. Объяснить это можно, в частности, тем, что при растворении кристалла, содержащего F-центры, происходит переход в раствор электронов, локализованных на анионных вакансиях. Эти сольватированные электроны, соединяясь с находящимися в растворе ионами $\mathrm{H}^{+}$, переводят его в атомарное состояние [12]. Образующийся во включении водород насыщает и пересыщает раствор и формирует пузырьки, которые наблюдаются во включениях.
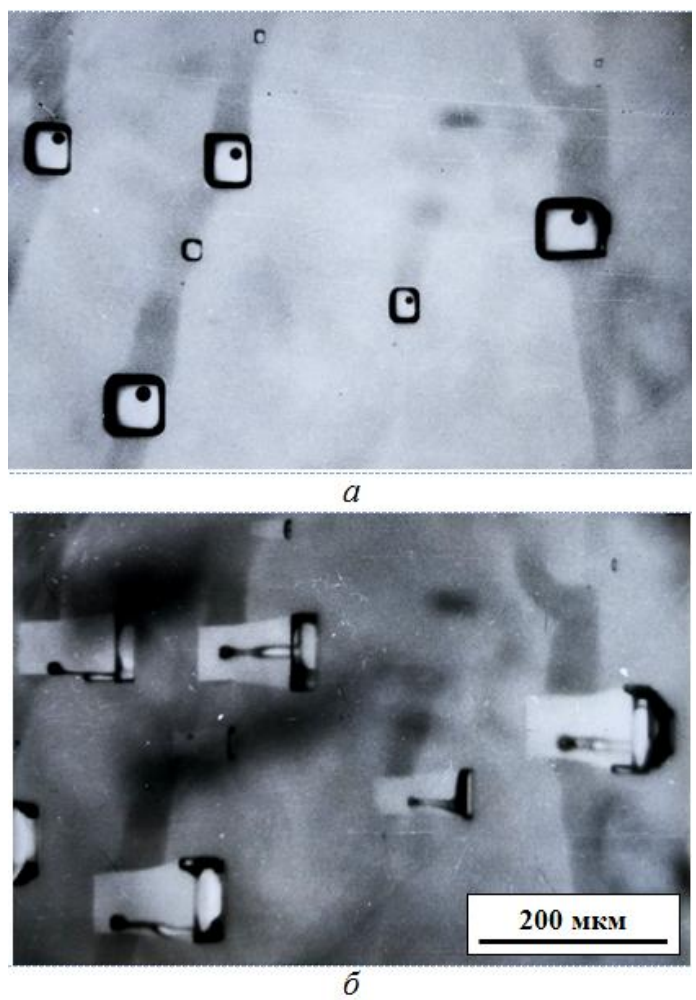

Pис. 2. Движение включений в поле $\nabla T$ в облученных кристаллах $\mathrm{KCl}$ :

$a$-исходное состояние; б-через 5 ч

Движение включений как в облученных, так и в аддитивно окрашенных кристаллах происходило в режиме граничной кинетики, характерном и для движения включений в кристаллах, не содержащих центры окраски [13]. Это означает, что диффузионный перенос вещества матрицы через объем включения не лимитирует процесс его движения. Вместе с тем средние значения скоростей включений одного размера в кристаллах с центрами окраски при прочих равных условиях оказались на $30 \ldots 50 \%$ выше, чем в чистых кристаллах. Это увеличение может быть связано с изменением структуры границы кристалл-раствор для окрашенных кристаллов. Тот факт, что такое изменение происходит, косвенно подтверждает отличие картин травления окрашенных и чистых кристаллов (рис. 3). Это также отчетливо видно при травлении скола облученного кристалла по плоскости, через которую прошло включение (рис. 4). Приведенные рисунки свидетельствуют о том, что не только дислокации, но и радиационные дефекты и их комплексы являются местами преимущественного травления поверхности кристалла KCl. Аналогичные картины травления наблюдали на поверхности монокристаллов $\mathrm{NaCl}$, облученных нейтронами [14].
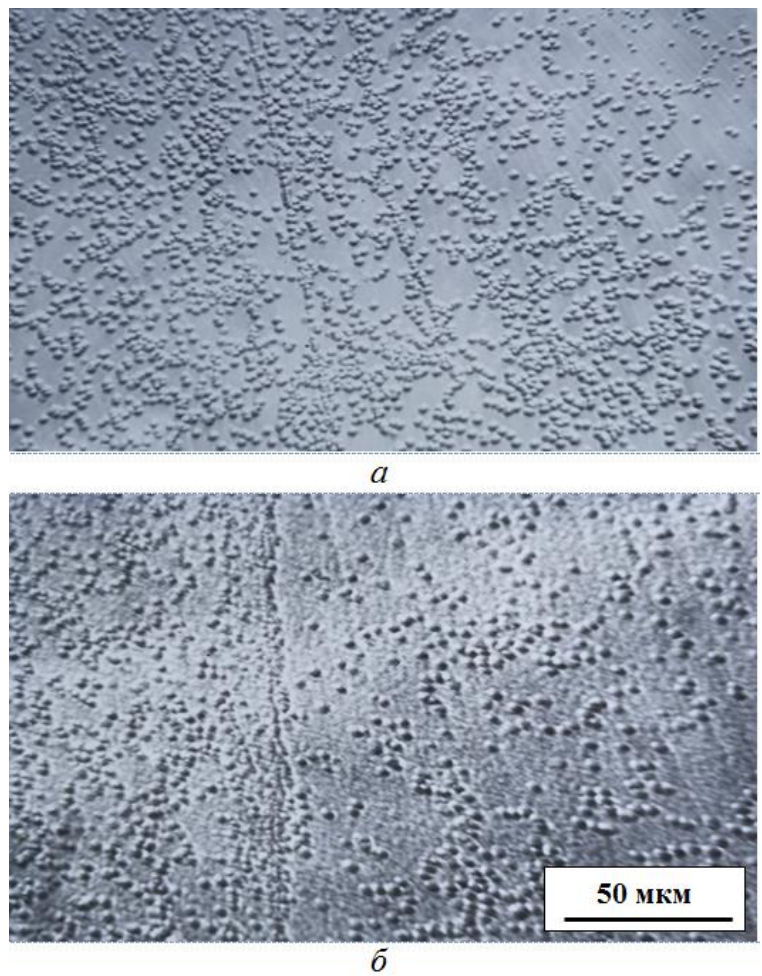

Рис. 3. Структура протравленной поверхности кристалла $\mathrm{KCl}$ до (а) и после (б) облучения

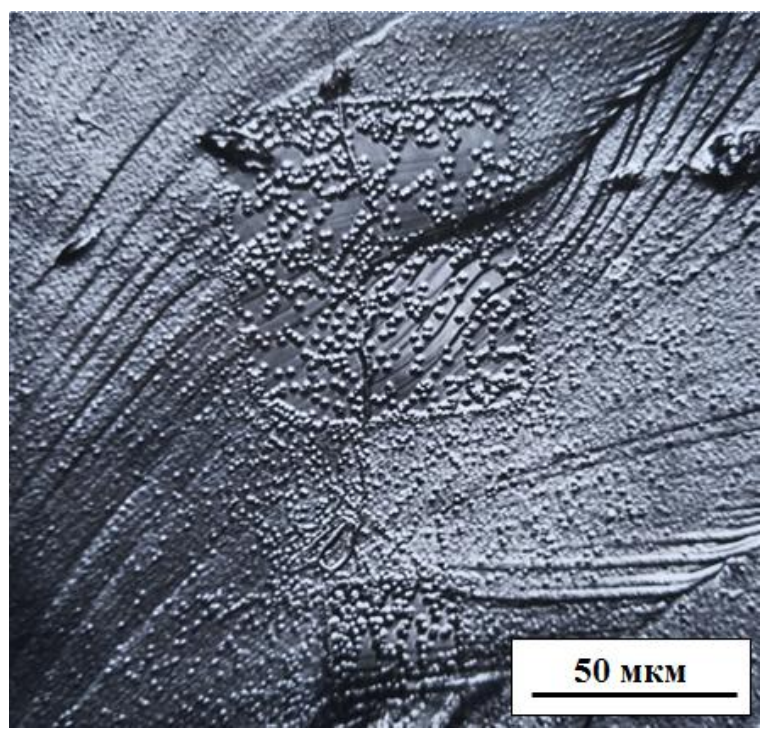

Рис. 4. Травление на дислокащии скола кристалла по плоскости, через которую прошли включения

В отличие от процесса облучения кристаллов, при котором кроме электронных образуются также дырочные центры окраски, в процессе аддитивного окрашивания кристаллов возникают только электронные центры окраски. Следовательно, факт увеличения скорости движения включений в 
образцах обоих типов свидетельствует о том, что именно их влияние на изменение структуры межфазной границы матрица-раствор является определяющим.

В отсутствие внешних силовых полей, воздействующих на кристалл, неизометричные включения (поры) самопроизвольно преобразуют свою форму, приближая ее к равновесной $[15,16]$. Эти процессы протекают в меру разности химических потенциалов атомов (молекул) $\Delta \mu=\gamma \Omega \Delta H$, обусловленной отличием локальных кривизн поверхности $\Delta H \quad(\gamma-$ поверхностное натяжение; $\Omega$ - объем, приходящийся на одну частицу в кристалле). Поскольку характерные недосыщения малы, движение ступеней, рождающихся на винтовых дислокациях, возможно только при условии, что расстояние от точки выхода дислокации до края грани или до выхода дислокации противоположного знака превосходит диаметр критического зародыша $d_{c}=2 \alpha \Omega / \Delta \mu$ ( $\alpha$-эффективное поверхностное натяжение ступени, определяемое как отношение ее линейного натяжения к высоте). В процессе релаксации величина $\Delta \mu$ уменьшается, а $d_{c}$ соответственно увеличивается, и на некоторой стадии процесс растворения (испарения) граней останавливается. Таким образом, процесс релаксации формы (как и процесс движения включений, пор) при послойном механизме в кристаллах без центров окраски является пороговым. Следует обратить особое внимание на тот факт, что движущая сила релаксации формы определяется поверхностным натяжением $\gamma$, а торможение процесса и его остановка зависят от величины $\alpha$. Этот факт позволяет по величине остаточной степени неизометричности включений (пор) получать информацию об отношении $\alpha / \gamma$ [15, 16], необходимом для понимания многих явлений на поверхности кристалла.

Наличие центров окраски оказывает существенное влияние на процесс релаксации в изотермических условиях формы включений, приобретенной при движении в поле температурного градиента. В чистом кристалле релаксация формы включения происходит путем растворения лобовой и тыльной граней и роста боковых граней. При этом центр масс включения практически не смещается. В облученном кристалле этот процесс происходит преимущественно путем растворения только лобовой грани (рис. 5). Кроме того, релаксация формы включений в облученных кристаллах происходит в значительно большей степени, чем в необлученных, зачастую практически приближаясь к равновесной форме.

Такое поведение включений может быть обусловлено, по меньшей мере, двумя причинами. Расчеты и опыты [14] показывают, что концентрация равновесного раствора над кристаллом в зависимости от его дефектности изменяется в большинстве случаев незначительно.
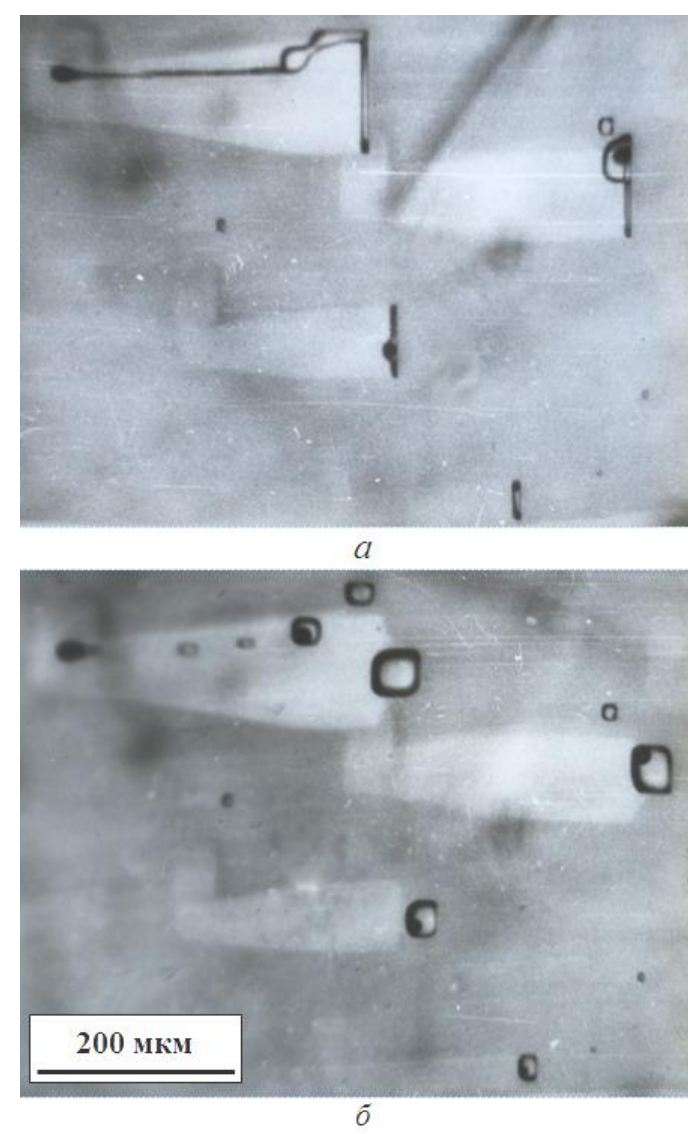

Рис. 5. Релаксация формы включений в облученном кристалле. Время релаксации 34 ч

Однако для жидкого включения, противолежащие грани которого находятся в неравнозначных условиях (одна грань содержит центры окраски, а другая - нет), это отличие может служить дополнительной движущей силой $\left(\Delta \mu_{F}\right)$ процессов растворения на лобовых гранях. Вторая причина может быть связана с тем, что кинетические коэффициенты ступеней, которые характеризуют скорость эмиссии частиц кристалла ступенью (или скорость их встраивания в ступень) и определяют скорость ее движения, имеют различные значения на поверхностях, граничащих с облученной областью кристалла и с перекристаллизованной областью. Величина кинетического коэффициента ступени при прочих равных условиях определяется концентрацией изломов на ступени. Очевидно, что F-центры, представляющие собой анионные вакансии, захватившие электрон, выходя на поверхность, увеличивают значения кинетических коэффициентов элементарных ступеней и повышают скорость растворения грани как целого.

Подводя итог, можно сделать вывод о том, что при достаточных концентрациях центров окраски в кристалле движение ступеней растворения на лобовой поверхности, граничащей с дефектной областью кристалла, будет возможным и при полной релаксации формы включения. Однако кристаллизация в этом случае будет происходить уже не на боковых гранях, а на тыльной грани, т. е. в отсутствие внешних силовых полей включение может начать смещаться как целое. 


\section{САМОПРОИЗВОЛЬНАЯ МИГРАЦИЯ ВКЛЮЧЕНИЙ В ОБЛУЧЕННЫХ КРИСТАЛЛАХ}

Рассмотрим жидкое включение в облученном кристалле. Предположим, что в результате флуктуации или кратковременного внешнего воздействия (например, температурного градиента, обусловленного неравномерным остыванием образца и подложки после облучения) произошла незначительная перекристаллизация вещества матрицы с одной поверхности включения на другую. Тогда, поскольку радиационные дефекты не воспроизводятся, возникает неравнозначность этих поверхностей, обусловленная отличием химических потенциалов атомов $\Delta \mu_{F}$ в облученной и перекристаллизованной областях кристалла. Если величина $\Delta \mu_{F}$ будет достаточной для того, чтобы вызвать движение ступеней растворения на какойлибо поверхности, граничащей с дефектной областью кристалла, то может происходить движение включения как целого.

Обсуждаемый тип движения включений наблюдался в облученных электронами монокристаллах $\mathrm{KCl}$ [10], в которых концентрации основных центров окраски - электронных F-центров и дырочных $\mathrm{V}_{3}$-центров - были примерно одинаковыми и равными $n \simeq 2 \cdot 10^{23} \mathrm{M}^{-3}$.

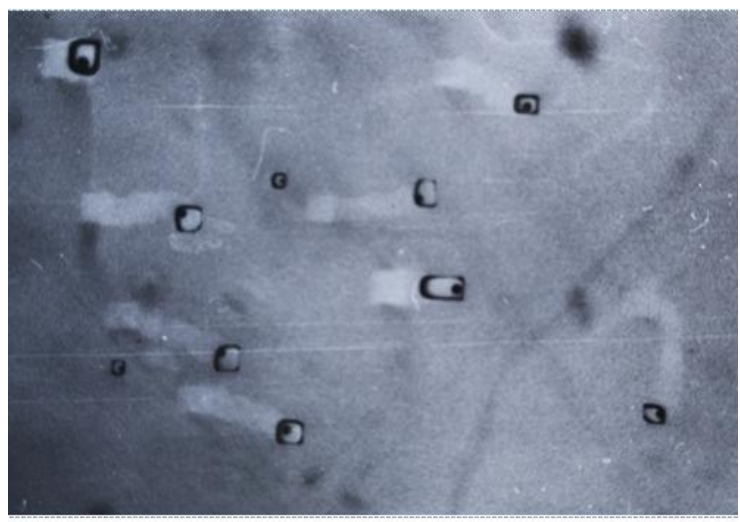

$a$

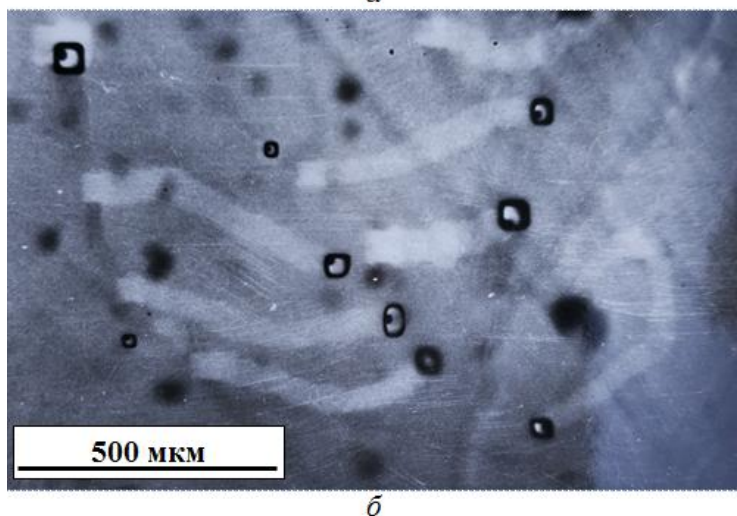

Рис. 6. Смещтение включений в облученном электронами кристалле в изотермических условиях: $a-9,6-25$ сут после облучения

После облучения кристаллы выдерживались в изотермических условиях при комнатной температуре в отсутствие внешних силовых полей. При этом происходило самопроизвольное движение включений (рис. 6). Скорость нормального растворения граней включений, приведенных на рис. 6, оказывается порядка одного монослоя в секунду. С течением времени скорость включений уменьшается, что, видимо, связано с общим уменьшением дефектности кристалла в процессе его длительной выдержки после облучения. О траектории движения включений можно легко судить по просветленным следам, образующимся за ними (рис. 7). Хаотический характер миграции обусловлен, по-видимому, тем, что из шести поверхностей, ограничивающих включение, только одна является выделенной (тыльной), а из пяти остальных будет растворяться та, на которой имеется более активный источник ступеней растворения. Таким источником является наиболее благоприятно расположенная и ориентированная винтовая дислокация. Различная активность дислокационных источников объясняет также значительный разброс скоростей включений, в связи с чем ранее приводились значения скоростей, усредненные по достаточно длинному промежутку времени - до одного месяца. По кинетике движения включений было вычислено повышение химического потенциала атомов кристалла, обусловленное радиационными дефектами $\Delta \mu_{F} \simeq q n \Omega$, на основании которого сделаны оценки $q$ - запасаемой энергии, приходящейся на один Fцентр. Полученное значение оказалось намного меньшим энергии, которая запасается в расчете на один F-центр при облучении кристалла $\mathrm{KCl}$ согласно результатам теоретических и экспериментальных исследований, представленных в [14], - $q \simeq 5$ эВ. Расхождение объяснялось отличием почти на два порядка концентрации центров окраски вблизи поверхности растворения от их концентрации в объеме кристалла. Такое отличие связывалось с возмущающим действием раствора на приповерхностный слой кристалла толщиной более $10 \mathrm{Hм,} \mathrm{в} \mathrm{котором} \mathrm{повышается} \mathrm{вероятность}$ туннельной рекомбинации электронных и дырочных центров между собой, а также с донорами и акцепторами, находящимися в приповерхностном слое раствора [17].

Чтобы более детально разобраться в движущих силах и кинетике самопроизвольной миграции жидких включений в кристаллах с точечными дефектами радиационного происхождения, необходимы дальнейшие исследования динамики этих процессов. В заключение следует отметить принципиальное отличие роли центров окраски, создаваемых при облучении кристалла, и центров окраски, возникающих при аддитивном окрашивании, в формировании движущих сил самопроизвольной миграции включений. Попытки вызвать самопроизвольную миграцию включений в аддитивно окрашенных образцах оказались нерезультативными. Очевидно, этот факт обусловлен тем, что во втором случае система «матрица-центры окраски» является термодинамически стабильной, а в первом термодинамически нестабильной. 

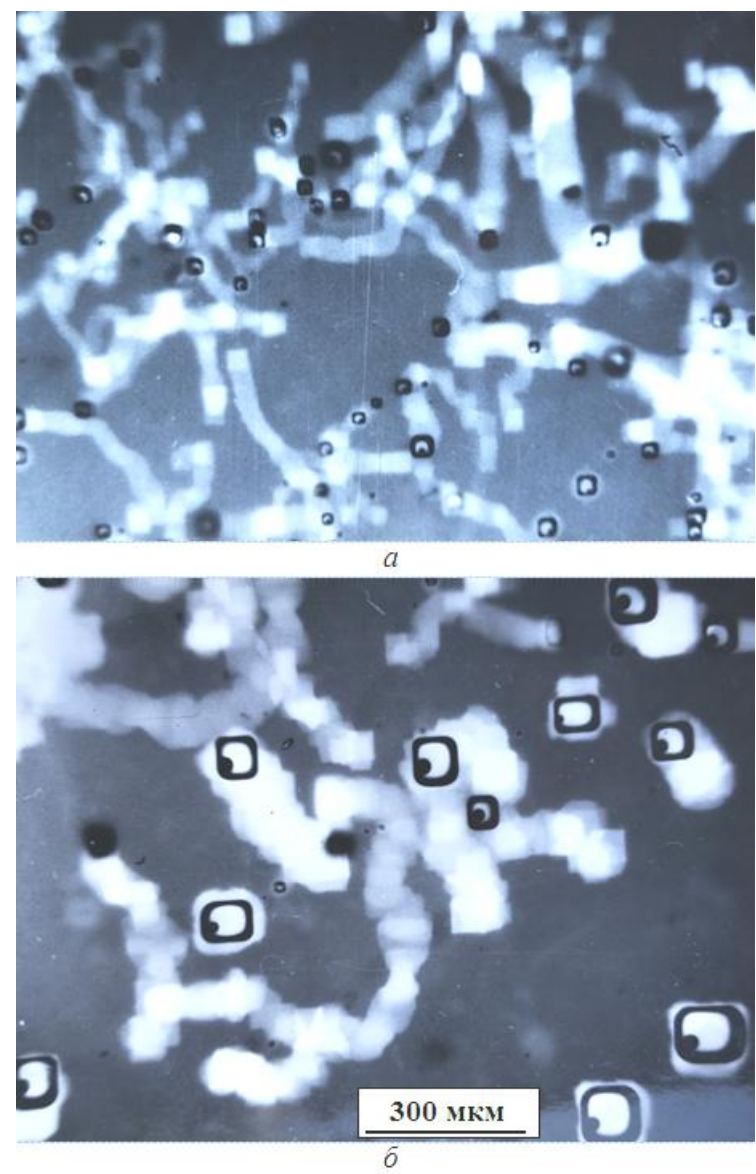

Рис. 7. Следы самопроизвольной миграчии включений различных размеров в облученном электронами кристалле.

Время после облучения 1 месяч

\section{ВЫВОДЫ}

В работе изучено радиационно-стимулированное поведение жидких включений в монокристаллах $\mathrm{KCl}$. Показано что под действием облучения включения становятся подвижными. Это может приводить к миграции таких объектов на границу материала и выходу радиоактивных элементов из захоронения. Исследованы траектории самопроизвольной миграции включений различных размеров в кристалле, облученном электронами.

Полученные данные важны для прогнозирования свойств хранилищ радиоактивных отходов.

\section{БИБЛИОГРАФИЧЕСКИЙ СПИСОК}

1. М. Томсон. Дефекты и радиационные повреждения в металлах. М.: «Мир», 1971, 398 с.

2. В.Ф. Зеленский, И.М. Неклюдов, Т.П. Черняева. Радиационные дефекты и распухание металлов. Киев: «Наукова думка», 1988, 296 с.

3. А.Л. Суворов. Автоионная микроскопия радиационных дефектов в металлах. М.: «Энергоатомиздат», 1982, 277 с.
4. Ш.Ш. Ибрагимов, В.В. Кирсанов, Ю.С. Пятилетов. Радиачионные повреждения металлов $и$ сплавов. М.: «Энергоатомиздат», 1985, 240 с.

5. В.В. Кирсанов, А.Л. Суворов, Ю.В. Трушин. Прочессы радиачионного дефектообразования в металлах, повреждения металлов и сплавов. М.: «Энергоатомиздат», 1985, 202 с.

6. C.L. Corkhill, D.J. Bailey, F.Y. Tocino, M.C. Stennett, J.A. Miller, J.L. Provis, N.C. Hyatt. Role of Microstructure and Surface Defects on the Dissolution Kinetics of $\mathrm{CeO}_{2}$, a $\mathrm{UO}_{2}$ Fuel Analogue // ACS Applied Materials \& Interfaces. 2016, v. 8(16), p. 10562-10571.

7. Г.Г. Леммлейн. Процесс залечивания трещины в кристалле и преобразование формы полостей вторичных жидких включений // ДАН СССР. 1951, т. 78, №4, с. 685-688.

8. А.А. Чернов. Процессы кристаллизации. Современная кристаллография. М.: «Наука», 1980, т. 3, c. 7-232.

9. В.С. Кружанов, О.В. Подшивалова. Определение кинетических коэффициентов растворения из опытов по движению жидких включений в кристаллах // Кристаллография. 1990, т. 35, №6, c. $1534-1539$.

10. В.С. Кружанов, О.В. Подшивалова. Движение жидких включений в кристалле, обусловленное радиационными дефектами // ФTT. 1990, т. 32, №2, c. $373-378$.

11. C. Z. Doorn. Method for heating alkali haloids and other solids in vapour of controlled pressure // Rev. Sci. Instrument. 1961, v. 32, N 6, p. 755-757.

12. Л.Т. Бугаенко, Ю.Е. Тиликс, К.К. Шварц. Возможности изучения электронных и дырочных дефектов в щелочно-галоидных кристаллах методом растворения. Радиационная физика. Рига, 1978, в. 7, c. $197-225$.

13. Я.Е. Гегузин, А.С. Дзюба, В.С. Кружанов. Исследование поведения жидких включений в кристалле в поле температурного градиента // Кристаллография. 1975, т. 20, в. 2, с. 383-391.

14. А.А. Воробьев, Е.К. Завадовская, А.В. Кузьмина. Запасенная энергия в щелочно-галоидных соединениях. Томск: Изд. ТГУ, 1969, 324 с.

15. Я.Е. Гегузин, В.С. Кружанов, Л.В. Старухина. Об изотермической релаксации формы неизомерного жидкого включения в кристалле // Кристаллография. 1988, т. 33, в. 6, с. 1505-1508.

16. Ю.С. Кагановский, В.С. Кружанов, А.П. Кулик. Релаксация формы неизометричных пор в монокристаллах $\mathrm{NaCl} / /$ Кристаллография. 1989, т. 34 , в. 6 , с. $1541-1547$.

17. Ю.Э. Авотиньш, Л.Т. Бугаенко, Ю.Р. Дзелме, Ю.Е. Тиликс. Лиолюминесиенциия. Рига: «Знание», 1984, 224 с. 


\section{РАДИАЦЙНО-ІНДУКОВАНИЙ РУХ РІДКИХ ВКЛЮЧЕНЬ У ЛУЖНО-ГАЛОЇДНИХ КРИСТАЛАХ}

\section{О.П. Кулик, О.В. Подиивалова, І.Г. Марченко}

Вивчено радіаційно-стимульовану поведінку рідких включень у монокристалах КСl. Показано, що під дією опромінення включення стають рухливими. Це може призводити до міграції таких об'єктів на межу матеріалу і виходу радіоактивних елементів із поховання. Досліджено траєкторії самочинної міграції включень різних розмірів у кристалах, опромінених електронами і $\gamma$-квантами.

\section{RADIATION-INDUCED MOUTION OF LIQUID INCLUSIONS IN ALKALI HALIDE CRYSTALS}

\section{O.P. Kulyk, O.V. Podshyvalova, I.G. Marchenko}

The radiation-stimulated behavior of liquid inclusions in $\mathrm{KCl}$ crystal was studied. It was shown that due to irradiation the inclusions become movable. It can result in the migration of such objects to the boundary of the material and the release of radioactive elements from the disposal. The trajectories of spontaneously migrating inclusions of various sizes were investigated in crystals irradiated by electrons and $\gamma$-quanta. 